\title{
Spatial Variance of Capelin (Mallotus villosus) in Coastal Newfoundland Waters
}

\author{
John K. Horne \\ Ocean Sciences Centre and Department of Biology, Memorial University of Newfoundland \\ St. John's, Newfoundland, Canada A1C 5 S7
}

\begin{abstract}
Quantitative description of scale-dependent spatial variance provides clues to biological and physical mechanisms that generate patchiness. Patterns of spatial variance among mobile organisms differ from passive tracers of the surrounding fluid. Scale-dependent spatial variance of capelin (Mallotus villosus), a mobile pelagic fish species, was compared to sea surface temperature in 32 transects surveyed along the northwestern shore of Conception Bay. Capelin spatial variance was concentrated at single scales in some transects but when 30 transects were averaged, decreased with a slope of -0.40 from $10 \mathrm{~km}$ to $200 \mathrm{~m}$ scales. Spatial variance of sea surface temperature decreased with an average slope of -1.35 . In the absence of strong horizontal temperature gradients, little evidence of anisotropic capelin distribution was observed in seven long- and cross-shore paired transects. Episodic scale dependence of capelin spatial variance suggests capelin-predator interactions are brief and occur over a wide range of spatial scales.
\end{abstract}

Key words: Anisotrophy, capelin, Newfoundland, spatial variance, surface temperature

\section{Introduction}

Capelin (Mallotus villosus) are traditionally found throughout Newfoundland coastal waters during late spring and early summer, where they support a large commercial fishery and are a major prey of Atlantic cod (Gadus morhua), seabirds and marine mammals. Fluctuating catch levels in passive fishing gear suggests that local capelin abundances vary over a broad range of spatial and temporal scales during this period. The quantification of spatial variance provides clues to mechanisms that generate observed physical and biological patchiness. Peaks in spatial variance patterns of passive tracers (e.g. sea surface temperature) at large scales are caused by turbulent kinetic energy which decreases or "cascades" to small scales (Okubo, 1980; Mackas et al., 1985). As an example, surface temperature spatial spectra peaked at a scale of $100 \mathrm{~km}$ and decreased with a slope of -2.2 in the Mediterranean Sea (Saunders, 1972) and -1.66 in the Antarctic Ocean (Weber et al., 1986). Phytoplankton spatial variance, a near-passive tracer of the surrounding fluid, also peaks at large scales with characteristic spectral slopes between -1.5 and -2.0 (Denman and Platt, 1974; Powell et al., 1975; Richerson et al., 1978; Weber et al., 1986). In contrast, spatial variance of mobile marine organisms is episodically concentrated at single scales (e.g. Grassle et al., 1975; Schneider and Duffy, 1985; Rose and Leggett, 1990). On average, spatial variance of at least one organism is relatively constant over large ranges of spatial scales (Weber et al., 1986). Krill (Euphausia superba) density in the Antarctic Ocean was concentrated at a single scale in some transects, but on average decreased with a slope of -0.18 from $100 \mathrm{~km}$ to $200 \mathrm{~m}$ scales (Weber et al., 1986; Levin et al., 1989). The difference between krill and surface temperature spectral slopes implies input of spatial variance by krill at small scales. Biological mechanisms capable of generating spatial variance include organism mobility and behavioral schooling. The purpose of this study was to determine if spatial variance patterns observed in krill also occur in schooling fish such as capelin.

Theory and observation suggest eastern and northeastern Newfoundland coastal waters have an anisotropic horizontal thermal structure - greater spatial variation across than along the continental shelf. The late spring to autumn pressure gradient caused by the Bermuda high results in episodic upwelling through local southwesterly winds (Frank and Leggett, 1982; Taggart and Leggett, 1987; Schneider and Methven, 1988) and propagating internal waves (Yao, 1986). The anisotropic physical structure of coastal waters is also augmented by the southward flow of the inshore branch of the Labrador Current (Petrie and Anderson, 1983). Anisotropic physical gradients have been shown to influence the distribution of phytoplankton (Iverson et al., 1979; Denman and Powell, 1984; Mackas et al., 1985), zooplankton (Herman et al., 1981; Mackas, 1984; Ibanez and Boucher, 1987), and seabirds (Schneider and Duffy, 1985; Briggs, 1986; Schneider et al., 1988). Little work has focused on anisotropic concordance of physical gradients and fish distribution (e.g. Olson and Backus, 1985). If capelin are stenothermal (Templeman, 1948; Scott 
and Scott, 1988; Rose and Leggett, 1989) and respond to displacements of horizontal (Buzdalin and Burmakin, 1976; Schneider and Methven, 1988) and vertical (Methven and Piatt, 1991) thermal gradients, then a horizontal concentrating of capelin is predicted at a warm/cold water front. The resulting capelin distribution is hypothesized to be patchy at the scale of upwelling cross-shore and patchy at the scale of a capelin aggregation longshore. Schneider and Methven (1988) and Schneider (1989) examined capelin distribution during upwelling and non-upwelling periods in the Avalon Channel. Capelin aggregations were concentrated at the warm/cold water interface at the scale of upwelling, but analyses were restricted to crossshore transects. The potential anisotropic distribution of capelin aggregations has not been examined in coastal Newfoundland waters.

This study describes long- and cross-shore spatial variability of capelin in relation to coastal sea-surface temperatures. Scale-dependent spatial variance patterns of active (capelin) and passive (sea surface temperature) tracers are compared over scales of $200 \mathrm{~m}$ to $10 \mathrm{~km}$. The distribution of capelin aggregations in synoptic long- and crossshore transect pairs are examined for anisotropy.

\section{Methods}

The survey was conducted along the northwestern shore of Conception Bay, Newfoundland, from Ochre Pit Cove to Bay de Verde (Fig. 1). Transects were oriented parallel and perpendicular to shore, the majority forming a large letter "E" (Fig. 1). Fishing gear in the area dictated proximity of long- and cross-shore transects to the coastline. Transect length was set at $10 \mathrm{~km}$, a distance corresponding to approximately twice the first internal radius of deformation (Rossby radius) at this latitude (Schneider and Methven, 1988).

Sea surface temperature $\left( \pm 0.1^{\circ} \mathrm{C}\right)$ was recorded at 60 sec. intervals using a surface towed thermistor. At the start and end of each acoustic transect, water column temperature $\left( \pm 0.1^{\circ} \mathrm{C}\right)$ was vertically profiled using an EIL MC5 Salinometer (calibrated to $0^{\circ} \mathrm{C}$ ). A survey speed of $3.6 \mathrm{~ms}^{-1}$ minimized water surface disturbance and disruption of near-surface capelin distribution. Echograms of capelin were obtained using a $50 \mathrm{kHz}$ Furuno 410 paper sounder with a beam angle of $19^{\circ}$. Interpretation of traces on echograms as capelin was supported by: simultaneous viewing of near-surface capelin aggregations and traces on echograms, capture of capelin using hook and line while recording traces on echogram, observation and sampling of capelin as the overwhelmingly dominant species in commercial traps in the sampling area, and similarity of echogram traces with those of capelin re-

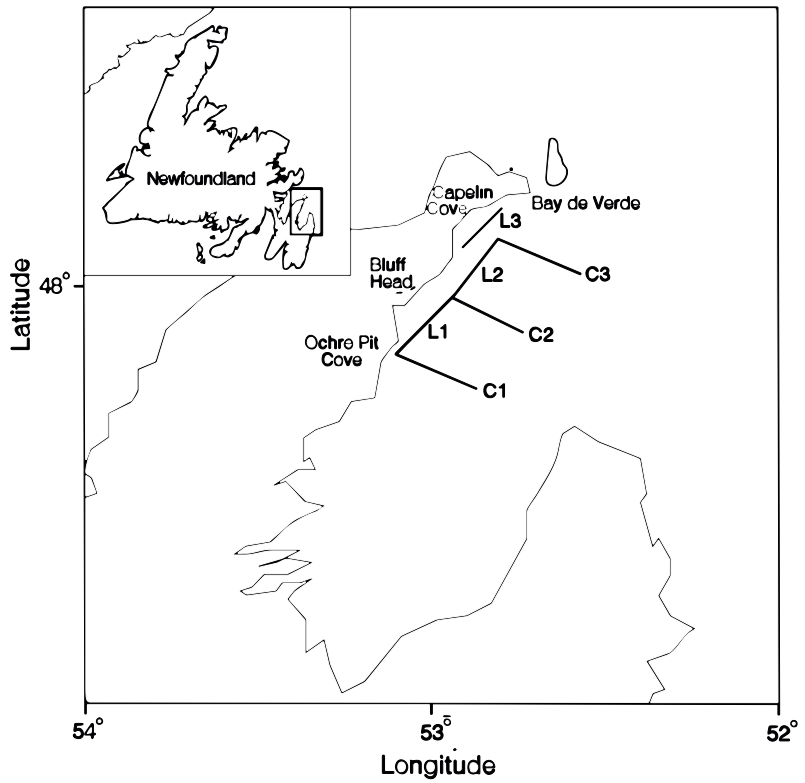

Fig. 1. Location of acoustic transects surveyed along the northwestern shore of Conception Bay, Newfoundland. L1, L2, and L3 are long-shore transects. C1, C2, and $\mathrm{C} 3$ are cross-shore transects.

ported in Newfoundland waters (Atkinson and Carscadden, 1979; Whitehead, MS 1981; Piatt, 1990). The number of discrete capelin aggregations were counted in $100 \mathrm{~m}$ horizontal by $5 \mathrm{~m}$ vertical blocks from the echogram of each transect. All transect records were scored by one reader and independently verified by another. Wave noise on sounder records was usually distinguishable from fish at the surface but if the two readers disagreed, traces were assumed to be wave noise. The use of a commercial echo-sounder precluded the calculation of absolute capelin abundance. Individual traces were scored equally with contiguous marks on the echogram. The equivalence of single and contiguous echogram traces may result in an underestimate of variance but this bias was assumed constant across all spatial scales.

Centred spectral analysis was used as an exploratory tool to examine scale-dependent spatial variability in capelin distribution and sea surface temperature data. The spectral density of a continuously recorded variable indicates how the variance of the data is distributed over a range of frequency bands (Jenkins and Watts, 1968; Chatfield, 1975). Spectral densities were estimated using the BMDP statistical package (Dixon, 1983) using three smoothing windows between 0.04 to 0.15 cycles $\mathrm{km}^{-1}$. A smoothing window of 0.10 cycles $\mathrm{km}^{-1}$ was judged to provide the best compromise between 
accuracy and smoothness, and was used in comparative analyses. All spectral density estimates were normalized to permit direct comparison of survey transects.

\section{Results}

A total of 32 transects, 20 long-shore and 12 cross-shore, were surveyed between 26 June and 15 July 1990 (Table 1). All transects were surveyed between dawn and dusk (05:30-21:30 NDT) over 3 week periods. Speed over bottom in all transects averaged $3.58 \mathrm{~ms}^{-1}$ with a range of $2.58 \mathrm{~ms}^{-1}$ to 5.01 $\mathrm{ms}^{-1}$. Spatial resolution of capelin distribution data is $100 \mathrm{~m}$ horizontal by $5 \mathrm{~m}$ vertical blocks with a corresponding horizontal temporal resolution of 27.9 sec. Transects were temporally separated by a mini- mum of 50 min while water column temperature was profiled.

The capelin distribution data were hypothesized to have a Poisson distribution. A G-test with Williams' correction (Sokal and Rohlf, 1981) was carried out on the frequency distribution of the raw data (3 664 blocks had 0 capelin present, 683 blocks had 1 group, 81 blocks had 2 groups and 6 blocks had 3 groups; coefficient of dispersion = 1.035). The observed distribution did not deviate significantly from a Poisson distribution $(\mathrm{G}=3.978$, $\mathrm{df}=$ $2, n=4434, p=0.1368$ ) allowing for a 5\% Type I error.

Centred, normalized capelin and surface temperature spectral density estimates were calculated

TABLE 1. Start and end locations of acoustic transects sampled in northwestern Conception Bay, 1990. Long-shore transects are designated L1, L2, or L3 followed by a transect number. Cross-shore transects are designated C1, C2, or C3 followed by a number. Sum is the total number of capelin aggregations observed over the length of the transect. Mean is the average number of capelin aggregations observed per $100 \mathrm{~m}$ horizontal block.

\begin{tabular}{|c|c|c|c|c|c|c|}
\hline Origin & End & Transect-Number & Date & Start time & Sum & Mean \\
\hline Ochre Pit Cove & Bluff Head & L1-1 & $26 / 6$ & $12: 35$ & 29 & 0.305 \\
\hline Bluff Head & Ochre Pit Cove & L1-2 & $26 / 6$ & $14: 00$ & 35 & 0.368 \\
\hline Ochre Pit Cove & Bluff Head & L1-5 & $27 / 6$ & $7: 56$ & 7 & 0.070 \\
\hline Ochre Pit Cove & Bluff Head & L1-7 & $4 / 7$ & 7:04 & 22 & 0.214 \\
\hline Ochre Pit Cove & Bluff Head & L1-11 & $4 / 7$ & $11: 13$ & 9 & 0.091 \\
\hline Ochre Pit Cove & Bluff Head & L1-15 & $5 / 7$ & $9: 48$ & 6 & 0.057 \\
\hline Ochre Pit Cove & Bluff Head & L1-19 & $12 / 7$ & $15: 32$ & 1 & 0.010 \\
\hline Bluff Head & Bay de Verde & L2-16 & $5 / 7$ & $10: 40$ & 26 & 0.260 \\
\hline Bluff Head & Bay de Verde & L2-20 & $12 / 7$ & $16: 28$ & 1 & 0.010 \\
\hline Bay de Verde & Bluff Head & L2-23 & $13 / 7$ & $8: 51$ & 75 & 0.528 \\
\hline Bluff Head & Bay de Verde & L2-26 & $13 / 7$ & $12: 28$ & 52 & 0.482 \\
\hline Bay de Verde & Bluff Head & L2-31 & $14 / 7$ & $5: 50$ & 42 & 0.372 \\
\hline Bluff Head & Bay de Verde & L2-32 & $14 / 7$ & 7:03 & 8 & 0.059 \\
\hline Bay de Verde & Bluff Head & L2-35 & $14 / 7$ & $18: 15$ & 59 & 0.450 \\
\hline Bay de Verde & Capelin Cove & L3-27 & $13 / 7$ & $13: 37$ & 19 & 0.275 \\
\hline Capelin Cove & Bay de Verde & L3-28 & $13 / 7$ & $15: 09$ & 24 & 0.338 \\
\hline Capelin Cove & Bay de Verde & L3-33 & $14 / 7$ & $8: 13$ & 11 & 0.149 \\
\hline Bay de Verde & Capelin Cove & L3-34 & $14 / 7$ & $9: 57$ & 12 & 0.200 \\
\hline Bay de Verde & Capelin Cove & L3-37 & $14 / 7$ & $20: 42$ & 41 & 0.300 \\
\hline Capelin Cove & Bay de Verde & L3-38 & $14 / 7$ & $21: 32$ & 40 & 0.571 \\
\hline Ochre Pit Cove & out & C1-3 & $26 / 6$ & $15: 15$ & 8 & 0.093 \\
\hline out & Ochre Pit Cove & C1-4 & $26 / 6$ & $16: 23$ & 13 & 0.130 \\
\hline out & Ochre Pit Cove & C1-10 & $4 / 7$ & $10: 12$ & 17 & 0.167 \\
\hline out & Ochre Pit Cove & C1-14 & $4 / 7$ & $14: 40$ & 3 & 0.031 \\
\hline Bluff Head & out & C2-8 & $4 / 7$ & $8: 07$ & 70 & 0.680 \\
\hline Bluff Head & out & $\mathrm{C} 2-12$ & $4 / 7$ & $12: 14$ & 20 & 0.194 \\
\hline Bluff Head & out & C2-24 & $13 / 7$ & $10: 35$ & 11 & 0.113 \\
\hline out & Bluff Head & C2-25 & $13 / 7$ & $11: 34$ & 16 & 0.170 \\
\hline Bay de Verde & out & C3-21 & $13 / 7$ & $6: 36$ & 29 & 0.246 \\
\hline out & Bay de Verde & C3-22 & $13 / 7$ & $7: 43$ & 52 & 0.416 \\
\hline Bay de Verde & out & C3-29 & $13 / 7$ & $15: 59$ & 5 & 0.051 \\
\hline out & Bay de Verde & C3-30 & $13 / 7$ & $16: 59$ & 13 & 0.161 \\
\hline
\end{tabular}


for transects having more than one capelin aggregation (30 of 32). Pattern detection in spectral density plots was partially dependent on presentation. Plots of spectral densities as a function of frequency (Fig. 2A) compressed spatial variability distribution patterns at frequencies less than 1 cycle $\mathrm{km}^{-1}$ and obscured patterns at frequencies greater than 1 cycle $\mathrm{km}^{-1}$. Common logarithms of spectral density estimates plotted as a function of frequency only expanded patterns at mid ( 1 cycle $\mathrm{km}^{-1}$ ) to high (5 cycles $\mathrm{km}^{-1}$ ) frequencies (Fig. 2B). Transforming spectral density estimates and frequencies to common logarithms (Fig. 2C) provided a workable compromise. The distribution of spatial variance was discernable at all frequencies and plots were comparable to those of Weber et al. (1986). The slope of the curve is equal to the exponent of a power function across all frequencies but areas under the curve do not represent equal contributions to the sample variance (Denman, 1975).

\section{Distribution of capelin spatial variance}

Spatial variability of capelin distribution in longand cross-shore transects was approximately uniform over scales ranging from $10 \mathrm{~km}$ to $200 \mathrm{~m}$ (Fig. $3 A-F)$. Spectral density estimates were larger and curves were smoother at frequencies less than 1 cycle $\mathrm{km}^{-1}$ in all six sets of long- and cross-shore transects. Episodic variation in any single transect was observed at frequencies greater than 1 cycle $\mathrm{km}^{-1}$. Using the colours of the visible spectrum to designate areas of variance, the slight negative slope and non-uniform variation at high frequencies is characterized as being pink with blue ripples. The distribution of spatial variance did not qualitatively differ between long- and cross-shore transects.

Consistent spectral density patterns were not observed among seven synoptic pairs of long- and cross-shore capelin distribution plots (Fig. 4). If capelin distribution is tightly coupled to near surface water temperatures, long-shore transects were predicted to have relatively constant variance over a large range of scales while cross-shore variance was predicted to peak at the frequency corresponding to the Rossby radius, approximately 0.2 cycles $\mathrm{km}^{-1}$ at $47^{\circ}$ North latitude. Cross-shore spectra exceeded long-shore spectra in only 4 of the 7 pairs at frequencies greater than 0.2 cycles $\mathrm{km}^{-1}$. Longand cross-shore spectra were highly variable at frequencies greater than 1 cycle $\mathrm{km}^{-1}$. Time intervals between long- and cross-shore transects did not exceed $75 \mathrm{~min}$. Little evidence of anisotropic capelin distribution was observed in long- and cross-shore transect pairs.

\section{Distribution of surface temperature spatial variance}

Long- and cross-shore surface temperatures were relatively constant throughout the survey period.
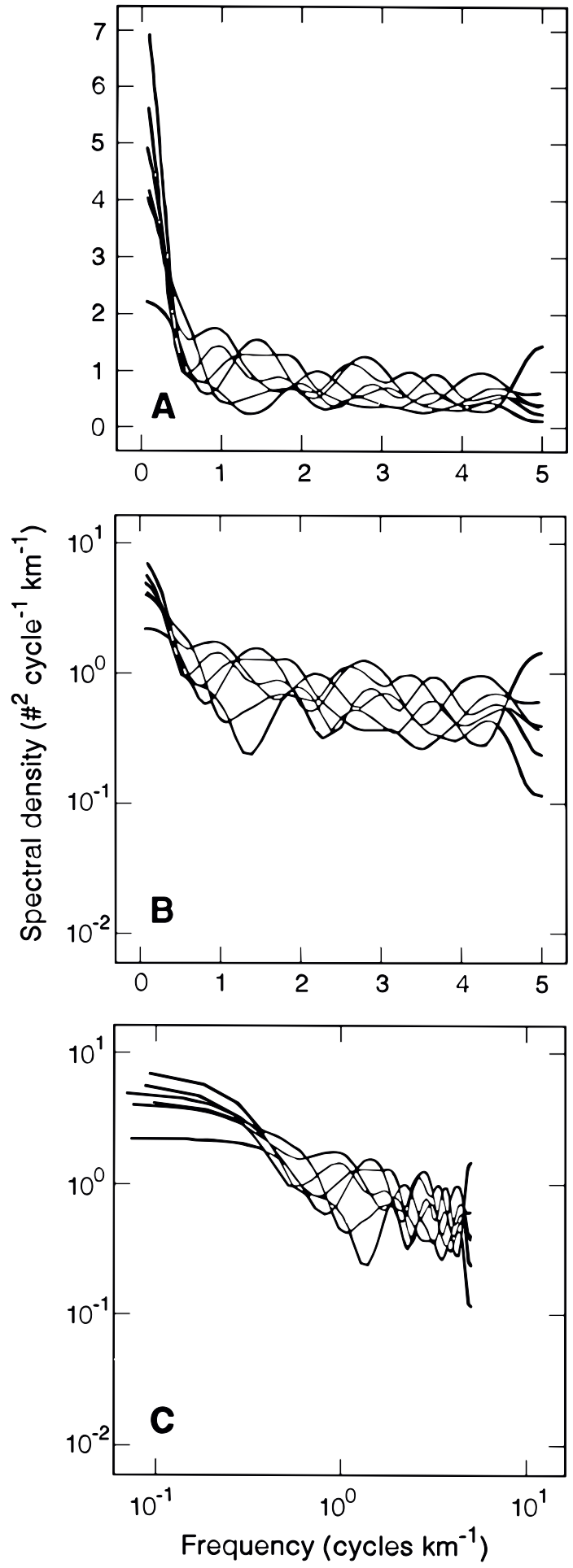

Fig. 2. Presentation of capelin aggregation spectral density estimates (bandwidth 0.10 , centred, normalized). (A) Raw spectral densities plotted as a function of frequency. (B) $\log _{10}$ spectral densities plotted as a function of frequency. (C) $\log _{10}$ spectral densities plotted as a function of $\log _{10}$ frequency. 


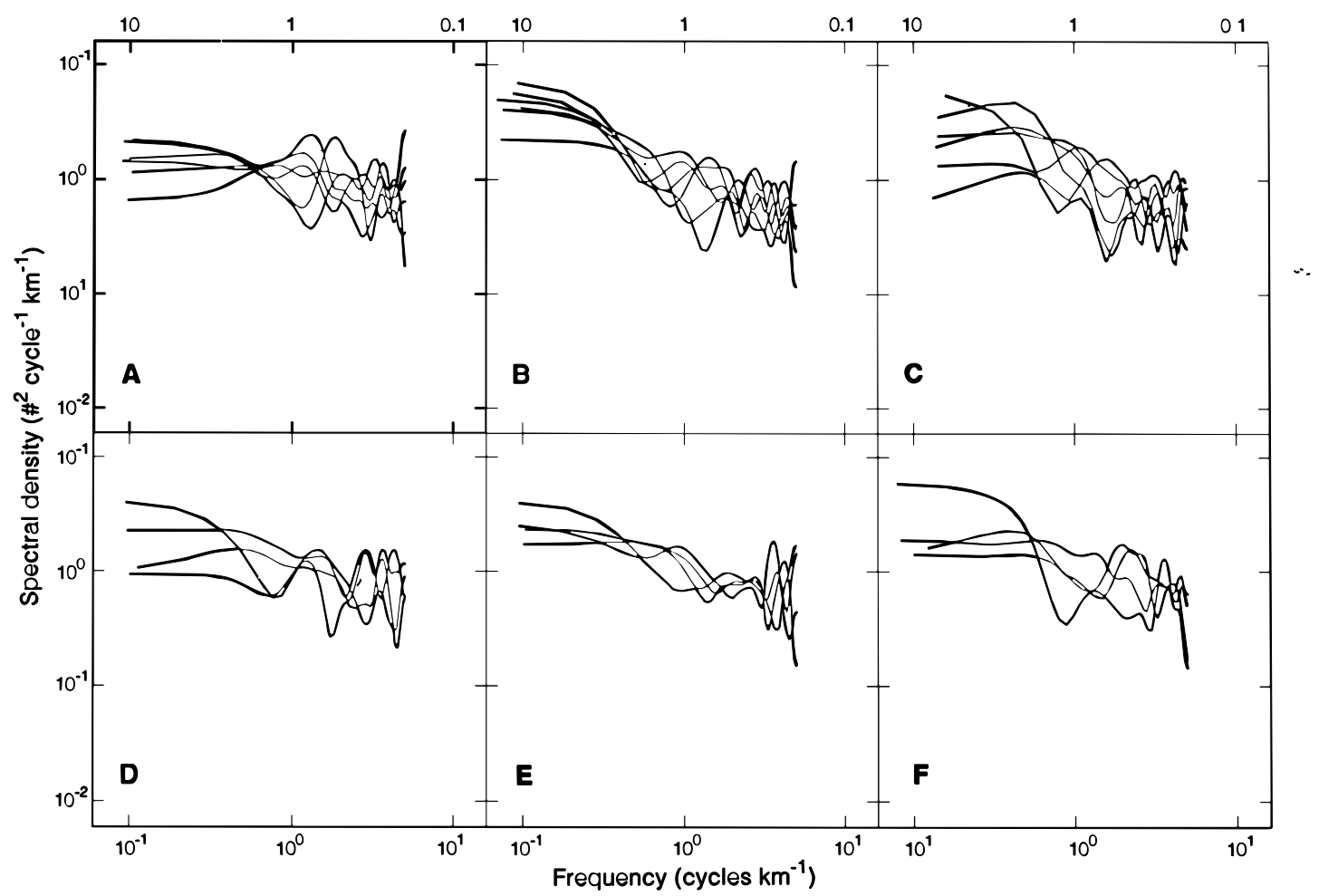

Fig. 3. Capelin aggregation spectral density estimates (bandwidth 0.10 , centred, normalized) plotted as a function of frequency. Long-shore transects (A-L1, B-L2, C-L3) are contrasted with cross-shore transects $(\mathrm{D}-\mathrm{C} 1, \mathrm{E}-\mathrm{C} 2, \mathrm{~F}-\mathrm{C} 3)$. Periods $(\mathrm{km})$ are shown on the upper $\mathrm{X}$ axis.

Values ranged from $7^{\circ}$ to a maximum of $11^{\circ} \mathrm{C}$. Temperature fluctuations on any repeated transect were limited to $2^{\circ} \mathrm{C}$ over the 3 week periods. Strong upwelling events, indicated by large cross-shore surface temperature discontinuities, were not observed at time of sampling. Vertical temperature profiles were also consistent throughout the study. A temperature drop of $7^{\circ} \mathrm{C}$ usually occurred in the upper $35 \mathrm{~m}$ with a strong thermocline forming between 15 and $25 \mathrm{~m}$. Transects surveyed during or immediately after wind events had uniform temperatures to $5 \mathrm{~m}$ depth, then dropped in a series of $1^{\circ} \mathrm{C}$ temperature steps for each $10 \mathrm{~m}$ in depth. Near bottom temperatures typically ranged between $0^{\circ}$ and $1^{\circ} \mathrm{C}$. Surface temperatures at inshore transects varied little or not at all within one day. Between days surface cooling or warming was observed, and between weeks surface temperatures fluctuated $2^{\circ} \mathrm{C}$ while all other depths warmed $3^{\circ}$ to $4^{\circ} \mathrm{C}$. Temperature sampling is considered synoptic over temporal scales of minutes, hours and days.

Surface temperature spectral density estimates among long- and cross-shore transects were greatest at the largest sampling scales $(10 \mathrm{~km})$ and generally decreased monotonically with sampling fre- quency (Fig. 5 A-F). Large portions of the sample variance were found at scales greater than $1 \mathrm{~km}$ in all six sets of long- and cross-shore transects. This pattern is a characteristic "red" spectrum, where large portions of the sample variance are found at low frequencies and rapidly decrease as frequency increases. Anisotropic surface temperature gradients predict longer dominant scales of spatial variance relative to cross-shore scales. Distinct peaks in cross-shore spectra at the scale of the Rossby radius $\left(0.2\right.$ cycles $\mathrm{km}^{-1}$ ) were not observed. Contrary to prediction, spectral density patterns observed in long-shore transects did not qualitatively differ from cross-shore transects.

\section{Comparison of active and passive tracers}

Average long- and cross-shore surface temperature spectral density plots were steeper than long- and cross-shore capelin distribution spectral density plots (Fig. 6). Surface temperature spectra spanned approximately 2.5 orders of spectral density magnitude with long-shore spectrum slope of -1.38 and a cross-shore spectrum slope of -1.31 . Average long-shore spectral density estimates were not significantly different from average cross-shore estimates $(F=0.01, p=0.906, n=98)$. Therefore, 


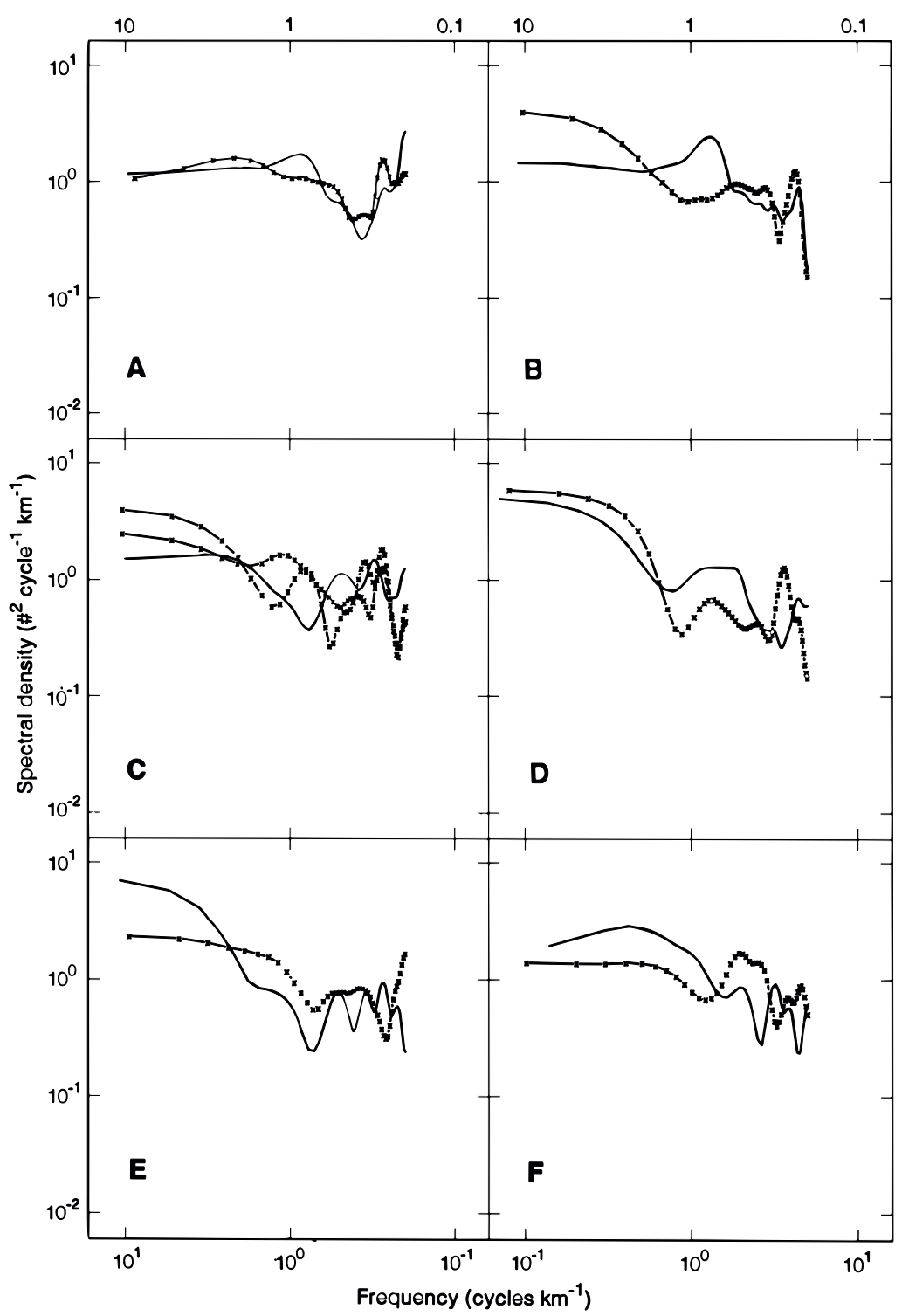

Fig. 4. Synoptic long-(solid line) and cross- (crossed line) shore capelin aggregation spectral density estimates (bandwidth 0.10 , centred, normalized) plotted as a function of frequency. Transect numbers correspond to those listed in Table 1. (A) Long-shore transect L12 , cross-shore transect C1-3. (B) Long-shore transect L1-7, crossshore transect C2-8. (C) Long-shore transect L1-11, cross-shore transects C1-10 and C2-12. (D) Long-shore transect L2-23, crossshore transect C3-22. (E) Long-shore transect L2-26, cross-shore transect C2-25. (F) Long-shore transect L3-28, cross-shore transect C3-29.

long- and cross-shore average spectral density estimates were used to calculate an overall surface temperature slope of -1.35 . Average long- and cross-shore capelin distribution spectra were much flatter than surface temperature spectra, spanning a single order of magnitude and having average slopes of -0.44 and -0.37 . Long-shore spectral density estimates did not differ from cross-shore estimates $(F=0.34, p=0.563, n=98)$ and were combined to calculate an average slope of -0.40 . 


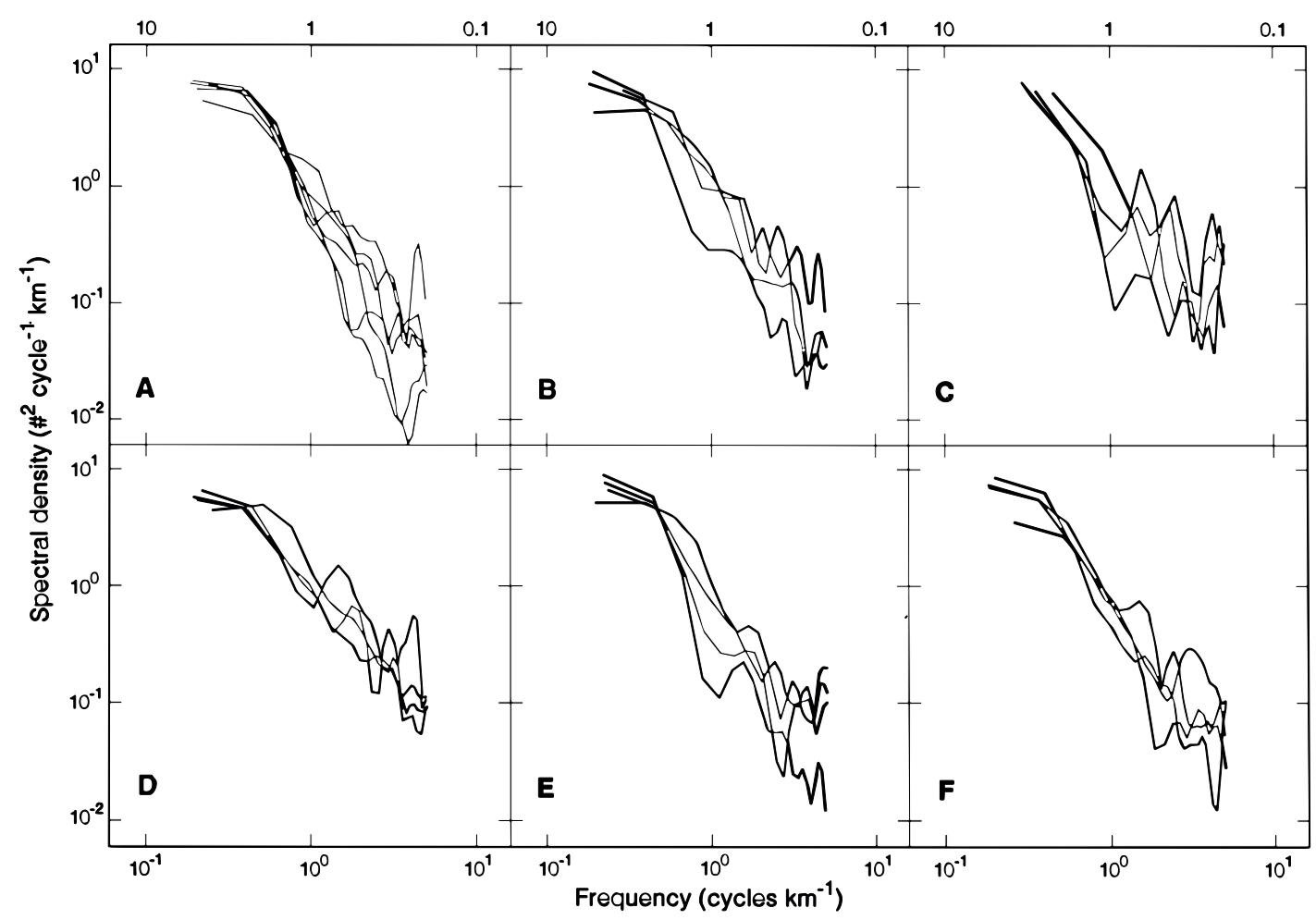

Fig. 5. Surface temperature spectral density estimates (bandwidth 0.10 , centred, normalized) plotted as a function of frequency. Long-shore transects (A-L1, B-L2, C-L3) are contrasted with cross-shore transects $(\mathrm{D}-\mathrm{C} 1, \mathrm{E}-\mathrm{C} 2, \mathrm{~F}-\mathrm{C} 3)$. Periods $(\mathrm{km})$ are shown on the upper $\mathrm{X}$ axis.

\section{Repeatability}

Observed isotropic capelin distribution patterns prompted questions of temporal distribution stability within the $10 \mathrm{~km}$ sample length. Plots of capelin aggregation abundance as a function of distance from origin were used to match capelin distributions along repeated transects. Twenty-two repeated transect pairs from the 30 transects had start time intervals ranging from $50 \mathrm{~min}$ to 17 hours. Based on the average speed of the survey vessel, a kilometre was travelled in $4.7 \mathrm{~min}$. Echograms of the two transects were overlaid and the absolute difference in number of capelin aggregations were enumerated in 4.7 min blocks. Differences in the number of capelin aggregations observed at the same location were predicted to increase as the time interval between two samples increased. The resulting plot showed no consistent divergence with time (Fig. 7). Differences at each block were assumed independent observations. However, a frequency histogram of the absolute differences in capelin abundances per block was not normally distributed. Association between time interval and absolute differences in capelin aggregations per 4.7 min block was assessed using Kendall's coefficient of rank correlation $(\tau)$. No significant correlations were found between the two variables when all transects were examined as a single group $(\tau=$ $0.0232, p=0.643, n=205)$, among long-shore transects $(\tau=0.00043, p=0.995, n=100)$, or when cross-shore transects were grouped together $(\tau=$ $0.0024, p=0.973, n=105$ ). Therefore, based on graphical interpretation and rank correlations, there was no observed increased divergence with increased start time interval among repeated transects.

\section{Discussion}

Average capelin spatial variance in 20 long- and 12 cross-shore transects decreased slightly between $10 \mathrm{~km}$ to $200 \mathrm{~m}$ scales. Cross-shore spectral density estimates were qualitatively similar to longshore estimates, indicating isotropic capelin variability during the sampling period. Large scale surface temperature variation exceeded small scale variation in all surveyed transects. Surface and vertical temperature profiles provided no evidence of upwelling along sampled transects.

Characteristic capelin aggregation sizes or inter-aggregation distances were not observed in long- or cross-shore composite spectral density 


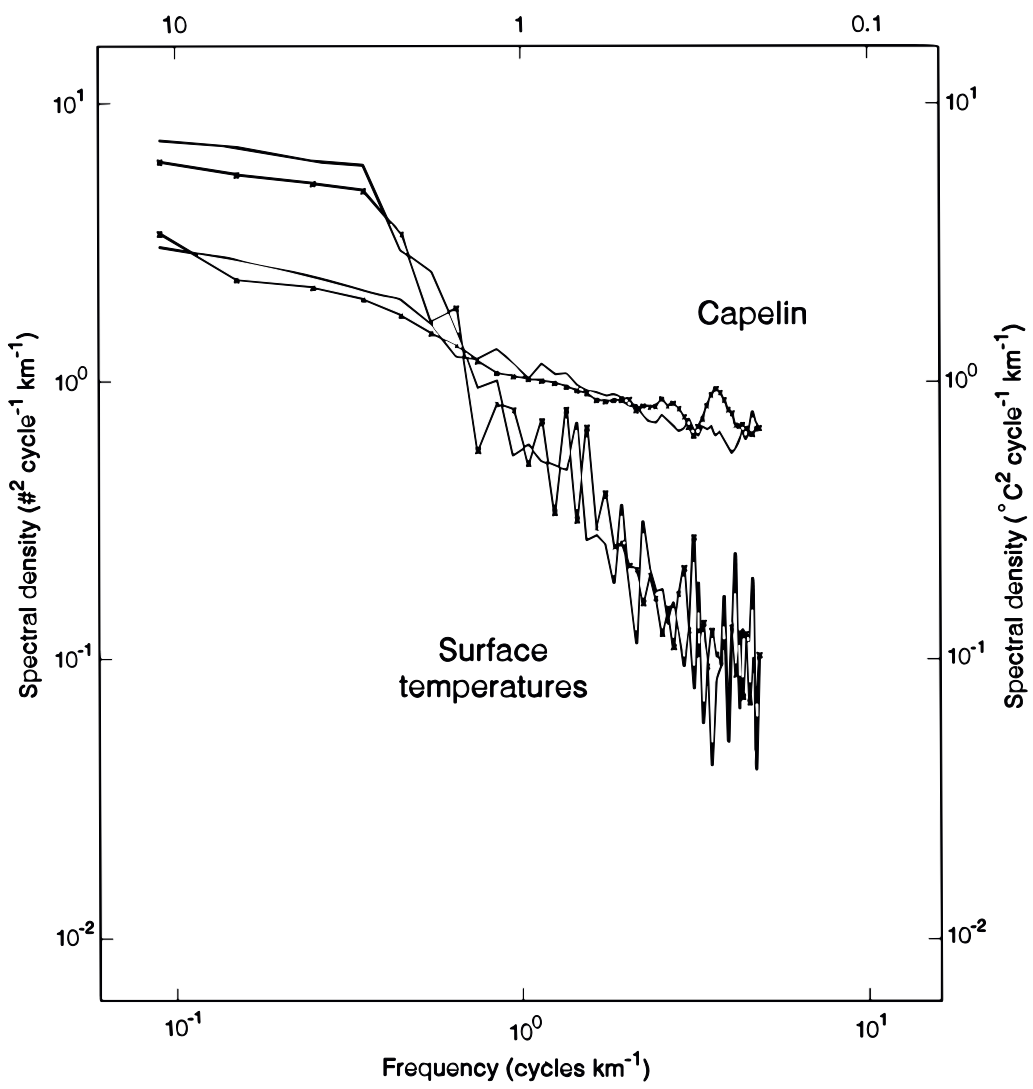

Fig. 6. Average capelin aggregation and surface temperature spectral density estimates (bandwidth 0.10 , centred, normalized) plotted as a function of frequency. Average long-shore estimates (solid line) are plotted with average cross-shore (crossed line) estimates.

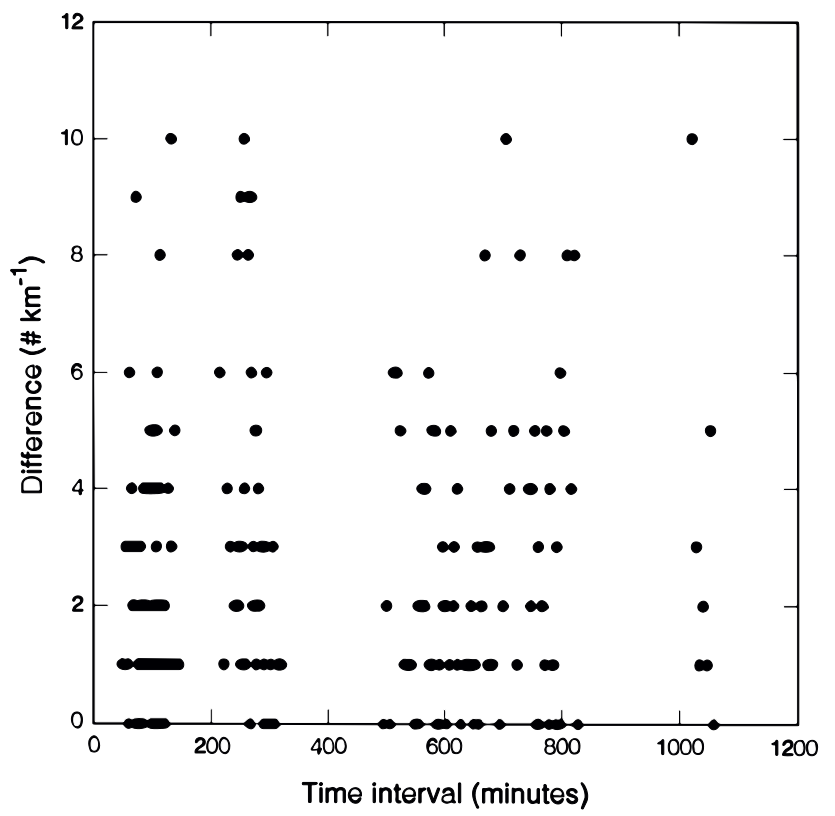

Fig. 7. Absolute difference in the number of capelin aggregations per $1 \mathrm{~km}$ horizontal block plotted as a function of elapsed time in 22 repeated transect pairs. 
plots. Scale-dependent peaks in spatial variance were observed in single transects, but these peaks occurred throughout the $10 \mathrm{~km}$ to $200 \mathrm{~m}$ scale range. In general, spectral density estimates were greatest at a scale of $10 \mathrm{~km}$ and decreased monotonically to a scale of $1 \mathrm{~km}$. At scales less than $1 \mathrm{~km}$, variable amplitude peaks were observed in all six sets of spectral density composite plots. This result contrasts with other studies in the Northwest Atlantic which identify characteristic capelin patch sizes. Schneider and Piatt (1986) report highly aggregated capelin schools ranging in size from 1.25 to $15 \mathrm{~km}$. Schneider (1989) also observed peaks in capelin spatial variance at 600-1 $000 \mathrm{~m}$ and $2-6 \mathrm{~km}$ in the Avalon Channel. The latter patch size matched the scale of wind induced upwelling at the study site. Aggregation dimensions of $3.5 \mathrm{~m}$ and $1-4 \mathrm{~km}$ were reported for capelin in the northern Gulf of St. Lawrence (Rose and Leggett, 1990). The present study indicates that characteristic capelin patch sizes are outside the range of sampling (larger than $10 \mathrm{~km}$ or smaller than $200 \mathrm{~m}$ ), are temporally very brief (on the order of minutes), or do not exist.

Little evidence was found to support the hypothesized anisotropic capelin distribution in nearshore waters. One possible explanation is the potential for large Type II error in non-synoptic long- and cross-shore paired transect data. A 3 hour time interval often occurred between the start of the first transect and the end of the second. Paired longand cross-shore transects were interrupted at their junction by a hydrography station that profiled water temperature. Given the swath width of the acoustic sampling cone, little lateral movement by capelin is required to change distributional patterns over a 3 hour sampling period. Alternatively, anisotropic distributions of capelin may be a response to horizontal thermal discontinuities caused by upwelling. While previous research has focused on capelin distributions in response to episodic upwelling events (e.g. Templeman, 1948; Schneider and Methven, 1988; Schneider, 1994), this study shows that predictable gradients in distribution do not occur during non-event periods. Observed surface and upper layer water temperatures on long- and cross-shore transects were within preferred temperatures $\left(5^{\circ}\right.$ to $\left.10^{\circ} \mathrm{C}\right)$ reported for capelin (Templeman, 1948; Rose and Leggett, 1989). Isotropic capelin distribution is expected in a homothermal upper water column and the orientation of capelin sampling is therefore not restricted by coastal configuration, unless strong upwelling conditions prevail.

Scale-dependent spatial variability of capelin and sea surface temperature were similar to those observed for krill and sea surface temperature in the Antarctic Ocean. Average long- and cross-shore capelin spectra had slight negative slopes and high frequency variation (pink spectra with blue ripples) while surface temperature spectra peaked at low frequencies and decreased monotonically to high frequencies (red spectra). Capelin spectral average slope $(-0.40)$ was steeper than the average $(-0.18)$ but within the range $(0.11$ to -0.70$)$ observed for krill (Weber et al., 1986; Levin et al., 1989). Similarly, Northwest Atlantic surface temperature spectral average slope $(-1.35)$ matched that of surface temperature spectral average slope (mean -1.66, range -0.74 to -2.48 ) in the Antarctic (Weber et al., 1986). The similarity of capelin and krill spectra and their contrast with surface temperature spectra is consistent with the proposal that mobility and schooling are capable of generating small scale spatial variance.

As a caveat, capelin and krill average spectral density slopes may not be directly comparable as it is unclear if krill data had low frequency variation removed (termed pre-whitening in spectral jargon) prior to spectral analysis. Capelin data were not prewhitened and may be aliased by spatial variance at frequencies below the sampling window. Potential aliasing of low frequency spectral density estimates was checked by combining the data from two consecutive long-shore transects. Capelin spectral density estimates of the combined transect exceeded those of composite or average capelin spectral densities at scales larger than $10 \mathrm{~km}$, indicating low frequency trends may still exist in the data.

Observations of pre-spawning capelin over a range of spatial scales has generated hypotheses on potential foraging strategies of capelin predators. At temporal scales of hours to weeks, the slight decrease in capelin spatial variance from large (10 $\mathrm{km})$ to small $(200 \mathrm{~m})$ scales indicates that net foraging benefits would be highest at the smallest scale that provides a full ration. Higher energetic demands coupled with small increases in capelin spatial variance would result in lower net foraging benefits if predators increase their average scale of foraging. Episodic concentrations of capelin spatial variance at single scales leads to the prediction that predators will shift to larger foraging scales to exploit temporally brief concentrations of capelin. Therefore, capelin-predator coherence is predicted to concentrate at large spatial scales at the temporal scale of a spawning season (approximately 6 weeks every year). However at the scale of a foraging bout (minutes to hours), coherence may be episodically concentrated at any single spatial scale.

\section{Acknowledgements}

This manuscript evolved steadily in consultation with D. Schneider. Funding was provided through 
the Ocean Production Enhancement Network (OPEN) and an A.G. Hatcher Memorial Scholarship to the author. I thank J. King and P. Normore for assistance in the field and scoring acoustic records. This is Ocean Sciences contribution 222.

\section{References}

ATKINSON, D. B., and J. E. CARSCADDEN. 1979. Biological characteristics of inshore capelin, Mallotus villosus (Müller), June-July 1977. Can. Tech. Rep. Fish. Aquat. Sci., 881: 18 p.

BRIGGS, K. T. 1986. Scales of patchiness in seabirds off central California. Pac. Seabird Group Bull., 13: 1920.

BUZDALIN, Y. I., and V. V. BURMAKIN. 1976. O svyazhi mezhdu temperaturoi poverkhnosti morya i plotnostyu skoplenii moivi v raione Nyufaundlenda. Tr. PINRO, Murmansk, 37: 57-60.

CHATFIELD, C. 1975. The analysis of time series: An introduction. Chapman and Hall, New York, NY, 286 p.

DENMAN, K. L. 1975. Spectral analysis: A summary of the theory and techniques. Can. Tech. Rep. Fish. Mar. Serv., 539: $27 \mathrm{p}$.

DENMAN, K. L., and T. PLATT. 1974. Coherence in the horizontal distributions of phytoplankton and temperature in the upper ocean. Proceedings of Sixth Liège Colloquium on Ocean Hydrodynamics. Mém. Soc. R. Sci. Liège, 6 sér., 8: 19-30.

DENMAN, K. L., and T. M. POWELL. 1984. Effects of physical processes on planktonic ecosystems in the coastal ocean. Oceanogr. Mar. Biol. Ann. Rev., 22: $125-168$.

DIXON, W. J. 1983. BMDP statistical software. Berkeley, University of California Press, $734 \mathrm{p}$.

FRANK, K. T., and W. C. LEGGETT. 1982. Coastal water mass replacement: its effect on zooplankton dynamics and the predator-prey complex associated with larval capelin (Mallotus villosus). Can. J. Fish. Aquat. Sci., 39: 991-1003.

GRASSLE, J. F., H. L. SAUNDERS, R. R. HESSLER, G. T. ROWE, and T. McLELLAN. 1975. Pattern and zonation: a study of the bathyal megafauna using the research submersible 'Alvin'. Deep Sea Res., 22: 457481.

HERMAN, A. W., D. D. SAMEOTO, and A. R. LONGHURST. 1981. Vertical and horizontal distribution patterns of copepods near the shelf break south of Nova Scotia. Can. J. Fish. Aquat. Sci., 38: 1065-1076.

IBANEZ, F., and J. BOUCHER. 1987. Anisotropy of zooplankton populations in the Ligurian Sea front. Oceanol. Acta., 10: 205-216.

IVERSON, R. L., T. E. WHITLEDGE, and J. J. GOERING. 1979. Fine-structure of chlorophyll and nitrate in the southeastern Bering Sea shelf break front. Nature, Lond., 281: 664-666.

JENKINS, G. M., and D. G. WATTS. 1968. Spectral analysis and its applications. Holden-Day, San Francisco, $535 \mathrm{p}$.

LEVIN, S. A., A. MORIN, and T. M. POWELL. 1989. Patterns and processes in the distribution and dynamics of Antarctic krill. SC-CAMLR-VII/BG/20 : 281-296.

MACKAS, D. L. 1984. Spatial autocorrelation of plankton community composition in a continental shelf ecosystem. Limnol. Oceanogr., 29: 451-471.

MACKAS, D. L., K. L. DENMAN, and M. R. ABBOTT. 1985. Plankton patchiness: Biology in the physical vernacu- lar. Bull. Mar. Sci., 37: 652-674.

METHVEN, D. A., and J. F. PIATT. 1991. Seasonal abundance and vertical distribution of capelin (Mallotus villosus) in relation to water temperature at a coastal site off eastern Newfoundland. ICES J. Mar. Sci., 48: 187-193.

OKUBO, A. 1980. Diffusion and ecological problems: mathematical models. Springer-Verlag, N.Y., 254 p.

OLSON, D. B., and R. H. BACKUS. 1985. The concentrating of organisms at fronts: a cold-water fish and a warm-core Gulf Stream ring. J. Mar. Res., 43: 113137.

PETRIE, B., and C. ANDERSON. 1983. Circulation on the Newfoundland continental shelf. Atmosphere-Ocean, 21: 207-226.

PIATT, J. F. 1990. The aggregative response of common murres and Atlantic puffins to schools of capelin. Stud. Avian Biol., 14: 36-51.

POWELL, T. M., P. J. RICHERSON, T. M. DILLON, B. A. AGEE, B. J. DOZIER, D. A. GODDEN, and L. O. MYRUP. 1975. Spatial scales of current speed and phytoplankton biomass fluctuations in Lake Tahoe. Science, 189: 1088-1090.

RICHERSON, P. J., T. M. POWELL, M. R. LEIGH-ABBOTT, and J. A. COIL. 1978. Spatial heterogeneity in closed basins.In: Spatial Pattern in Plankton Communities. J.H. Steele (ed.) Plenum Press, New York, p. 239276.

ROSE, G. A., and W. C. LEGGETT. 1989. Interactive effects of geophysically-forced sea temperatures and prey abundance on mesoscale coastal distributions of a marine predator, Atlantic cod (Gadus morhua). Can. J. Fish. Aquat. Sci., 46: 1904-1913.

ROSE, G. A., and W. C. LEGGETT. 1990. The importance of scale to predator-prey spatial correlations: An example of Atlantic fishes. Ecology, 71: 33-43.

SAUNDERS, P. M. 1972. Space and time variability of temperature in the upper ocean. Deep-Sea Res., 19: 467480.

SCHNEIDER, D. C. 1989. Identifying the spatial scale of density-dependent interaction of predators with schooling fish in the southern Labrador Current. J. Fish Biol., 35: 109-115.

SCHNEIDER, D. C. 1994. Distribution of capelin (Mallotus villosus) in relation coastal upwelling in the Avalon Channel. J. Northw. Atl. Fish. Sci., this volume, p. 2331.

SCHNEIDER, D. C., and D. C. DUFFY. 1985. Scale-dependent variability in seabird abundance. Mar. Ecol. Prog. Ser., 25: 211-218.

SCHNEIDER, D. C., and J. F. PIATT. 1986. Scale-dependent correlation of seabirds with schooling fish in a coastal ecosystem. Mar. Ecol. Prog. Ser., 32: 237246.

SCHNEIDER, D. C., D. C. DUFFY, and G. L. HUNT. 1988. Cross-shelf gradients in the abundance of pelagic birds. Proceedings XIX International Ornithological Congress: $976-981$.

SCHNEIDER, D. C., and D. A. METHVEN. 1988. Response of capelin to wind-induced thermal events in the southern Labrador Current. J. Mar. Res., 46: 105-118.

SCOTT, W. B., and M. G. SCOTT. 1988. Atlantic Fishes of Canada. Can. Bull. Fish. Aquat. Sci., 219: 731 p.

SOKAL, R. R., and F. J. ROHLF. 1981. Biometry. 2nd ed. Freeman, New York. 859 p.

TAGGART, C. T., and W. C. LEGGETT. 1987. Wind-forced hydrodynamics and their interaction with larval fish 
and plankton abundance: a time-series analysis of physical-biological data. Can. J. Fish. Aquat. Sci., 44: 438-451.

TEMPLEMAN, W. 1948. The life history of the capelin (Mallotus villosus Müller) in Newfoundland waters. Res. Bull. Dept. Natural Resources, Nfld., 17: 151 p. WEBER, L. H., S. Z. EL-SAYED, and I. HAMPTON. 1986. The variance spectra of phytoplankton, krill and water temperature in the Antarctic Ocean south of Africa. Deep-Sea Res., 33: 1327-1343.

WHITEHEAD, H. P. MS 1981. The behaviour and ecology of the humpback whale in the northwest Atlantic. PhD. thesis. University of Cambridge. $149 \mathrm{p}$.

YAO, T. 1986. The response of currents in Trinity Bay, Newfoundland, to local wind forcing. Atmosphere-Ocean, 24: $235-252$. 
Blank 